Article

\title{
Farmer's Knowledge and Perceptions on Rice Insect Pests and Their Management in Uganda
}

\author{
Simon Alibu*, Michael H. Otim, Stella E. A. Okello, Jimmy Lamo, Moses Ekobu \\ and Godfrey Asea
}

National Crops Resources Research Institute (NaCRRI), Namulonge, P.O. Box 7084, Kampala, Uganda; motim9405@gmail.com (M.H.O.); seokello@gmail.com (S.E.A.O.); lamojim@gmail.com (J.L.);

ekobum@yahoo.com (M.E.); grasea9@gmail.com (G.A.)

* Correspondence: simoalibu@hotmail.com; Tel.: +256-772-397674

Academic Editor: Les Copeland

Received: 21 March 2016; Accepted: 30 May 2016; Published: 17 August 2016

\begin{abstract}
Rice is a new crop in Uganda, but has quickly grown in importance. Between 2000 and 2010, total area under rice cultivation in the country grew by $94 \%$ from 140,000 ha. Changes in the agro ecosystem due to expansion in rice area may have altered the pest status of rice insect pests. However, far too little attention has been paid to assessing the prevalence and importance of rice insect-pests in Uganda. In this study, we interviewed 240 lowland-rice farming households from eight districts within the north, east and central regions of Uganda about their perceived insect-pest problems and control measures employed, if any. A semi-structured questionnaire was used. The farmers ranked rice insect pests as the most important biotic constraint in rice production, with stem borers and the African rice gall midge (AfRGM) perceived to be the 1st and 2nd most detrimental insect pests, respectively. In spite of this, only $36 \%$ of the respondents could positively identify symptoms of AfRGM damage on rice plants, while $64 \%$ were familiar with stem borer damage. Over $60 \%$ of interviewed farmers expressed confidence in the effectiveness of insecticides for controlling rice insect pests. Cultural control measures were not popular among the farmers.
\end{abstract}

Keywords: Uganda; rice field pests; farmer perceptions; alternative hosts; IPM

\section{Introduction}

Rice is a relatively new crop in Uganda, but has quickly grown in importance. The importance of rice in Uganda is highlighted in the national rice development strategy (NRDS), which seeks to make the country self-sufficient in rice by doubling production from 177,800 Mt in 2008 to $680,000 \mathrm{Mt}$ by 2018 [1]. Projections in the NRDS indicate that doubling rice production will respond to the increasing demand of Ugandans for rice. Per capita annual consumption of rice in Uganda went up from $3 \mathrm{~kg}$ in 1990 to $8 \mathrm{~kg}$ in 2010, representing a 62.5\% rise. Correspondingly, total area under rice cultivation in Uganda increased by over 70\% from 39,000 ha in 1990 to 140,000 ha in 2010 [2]. The rapid increase in the area under rice cultivation is largely attributed to the introduction of upland NERICA (New Rice for Africa), which found a niche especially among farmers who until recently thought of rice as a crop adapted only to irrigated/rainfed lowland ecosystems such as Kibimba, Doho, Olweny, and Agoro irrigation schemes. Today, many small-scale farmers can be found growing rice across the country alongside a few large scale rice growers. This out-scaling of rice cultivation into areas that were initially thought of as "non-rice producing regions" makes it increasingly difficult to ignore emerging biotic constraints or yield-reducing factors like pests, diseases and weeds, which may jeopardize future productivity. Insect pests constitute one of the major yield reducing factors in rice [3]. Crop losses due to insect pests on rice in the developing countries of Africa have been estimated at about 20\% [4]. In 2008, about half of the rice farmers in Sub Saharan Africa (SSA) experienced insect 
pest attacks, affecting $27 \%$ of the rice area and causing an estimated $20 \%$ yield loss [4]. However, rice insect pests can cause even much higher yield losses. For instance, yield losses of up to $45 \%$ were reported in Kenya [4]. Recent developments in the rice industry in Uganda have heightened the need to understand key insect-pest threats on rice and the yield losses that they cause, in addition to exploring available management options. This is against the background that the increasing area under rice production in Uganda may have altered insect pest complexes and changed the pest status of some insects. Thus, the purpose of this study was to assess farmers' knowledge and perceptions about rice insect pests, and how they manage rice insect pests. Understanding farmers' perceptions is important in guiding the development of sustainable and cost effective integrated pest management (IPM) strategies. Sound pest management practices can stabilize and secure rice production, to the benefit of the poor rice-farming households [5,6]. Moreover, farmer pest management strategies identified in this study (if any) may accelerate technology development and promotion, since farmer pest management practices represent the direct result of decisions they make every season to enable them to remain in production.

\section{Materials and Methods}

\subsection{Study Area}

The survey was conducted in the north, east and central regions of Uganda. Four districts were selected from the north, i.e., Lira, Dokolo, Otuke and Alebtong; three districts from the east, i.e., Iganga, Bugiri and Kamuli; and one district from the central area, i.e., Kayunga (Figure 1).

The north and east had a larger share of selected districts because they have a long history of lowland rice cultivation, which started in the 1950s with the establishment of Kibimba, Doho and Olweny irrigation schemes. Lowland rice cultivation is only a recent phenomenon in the central region. From each district, one rice producing sub county was selected; Barr for Lira district; Agwata for Dokolo district; Okwang for Otuke district; Apala for Alebtong district; Bukanga for Iganga district, Nabukalu for Bugiri district, Butansi for Kamuli district and Kangulumira for Kayunga district, altogether totaling to eight sub-counties. Within each sub county, three parishes were selected and 10 households drawn from each parish, constituting an overall total of 240 households.

\subsection{Survey Method and Data Analysis}

Rice-farming households were interviewed using a semi-structured questionnaire that was developed by a multi-disciplinary team comprising socio-economists, agronomists, entomologists and breeders. Before beginning the survey, the questionnaire was first pre-tested in Luwero District and then reviewed-based on pre-test findings. The review enabled clarification and streamlining of the interview questions for a smooth interviewing process. During the interviews, farmers were asked about their age, level of education, years of farming experience and their land tenure. They were also asked about their experiences with rice farming. Open-ended and closed questions were used to determine their knowledge and perceptions on a range of issues that included general and biotic constraints in rice production as well as insect pest problems. The farmers were showed pictures of rice insect pests and then asked to identify the pests and indicate the damage that the insect pests cause. They were then asked to rank the production constraints and rice insect pests in order of importance ( 1 being most important and 5 least important), and then indicate how they manage the rice insect pests, their source of information on how to manage rice insect pests, and effectiveness of the management options. A weighting score was used to determine overall importance of the various rice insect pests. The weight score of an insect pest was computed by multiplying its rank weight by the frequency with which it is cited by respondents. For instance, the most important insect pest was assigned the highest rank weight, while the least important insect pest was assigned the lowest rank weight of 1 . A weight score was then calculated by multiplying the rank weight of a variable by its 
response frequency, and the various weight scores summed up to give the total weight score. Farmer's knowledge and perceptions of weeds as alternate hosts of rice insect pests was also sought.

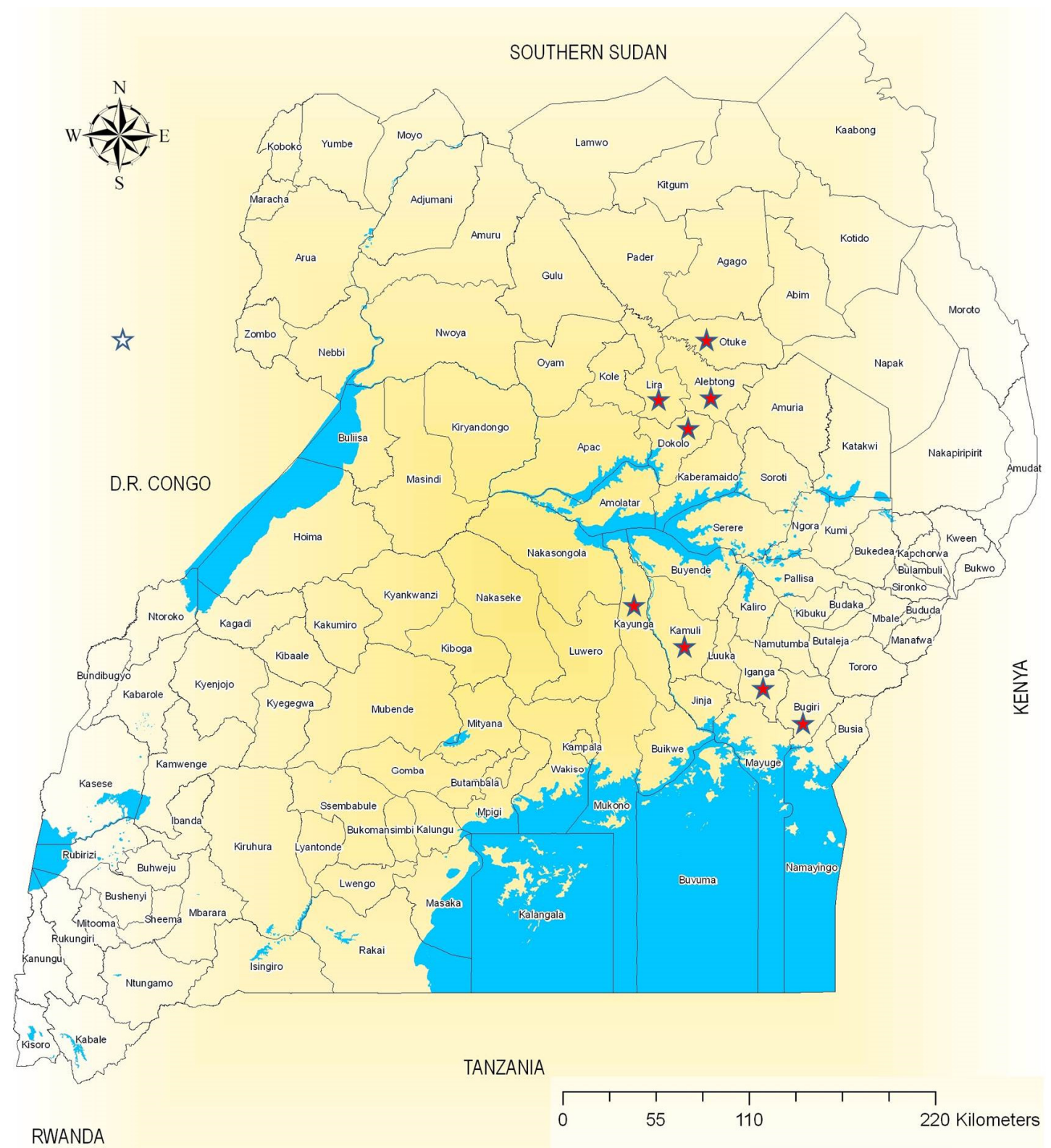

Figure 1. Map showing all districts in Uganda. Districts that were surveyed are marked with red stars.

Responses to the questions were coded before analysis. The open-ended questions were critically analyzed to identify recurrent themes which could be quantified to determine farmers' knowledge and perceptions. The statistical analysis was performed using Stata 10 [7], and statistics such as frequency distributions and percentages were used to analyze and report responses from the farmers.

\section{Results}

\subsection{Farmers Socio-Economic Profile}

Table 1 summarizes the socio-economic profile of the farmers interviewed. One third of the farmers were female. Approximately, sixty two percent (61.7\%) of the respondents were aged between 18 and 40 years while $35.6 \%$ fell within the $41-50$ years age bracket. Only $2.7 \%$ of the respondents 
were over 60 years of age. Almost two thirds $(61.6 \%)$ of the respondents went to primary school whereas $24.1 \%$ attended secondary school. A minority of the farmers (12.9\%) interviewed indicated not getting any formal education and a negligible number (3) had attended college/university.

Overall, the average land holding of the respondents was 6.4 acres. However, land holding varied from region to region. Farmers in the northern region owned larger pieces of land on average when compared to their counterparts in the east and central regions (Table 2).

Figure 2 compares the rice-growing experience of farmers in the three regions that were surveyed. Generally, most of the farmers had between 0-10 years of experience in rice farming. Clearly, farmers in Eastern Uganda had the longest history of rice cultivation as indicated by their relatively higher response percentage in the 16-20 and $>20$ years' experience-categories. In contrast, farmers from the central region were the least experienced. None of the farmers in the central region had more than 10 years' experience in rice cultivation.

Table 1. Socio-economic profile of the respondents.

\begin{tabular}{|c|c|c|}
\hline \multirow{2}{*}{ Characteristics } & \multicolumn{2}{|c|}{ Summary of Responses } \\
\hline & Response Frequency ( $n$ ) & Response Percentage (\%) \\
\hline \multicolumn{3}{|l|}{ Sex } \\
\hline Female & 69 & 30.8 \\
\hline Male & 155 & 69.2 \\
\hline \multicolumn{3}{|l|}{ Age (years) } \\
\hline $18-30$ & 68 & 30.6 \\
\hline $31-40$ & 69 & 31.1 \\
\hline $41-50$ & 50 & 22.5 \\
\hline $51-60$ & 29 & 13.1 \\
\hline$>60$ & 6 & 2.7 \\
\hline \multicolumn{3}{|l|}{ Level of Education } \\
\hline No Education & 29 & 12.9 \\
\hline Primary & 138 & 61.6 \\
\hline Secondary & 54 & 24.1 \\
\hline College/University & 3 & 1.3 \\
\hline
\end{tabular}

Table 2. Average land holding of the respondents by district and region.

\begin{tabular}{cccc}
\hline \multirow{2}{*}{ Region } & District & \multicolumn{2}{c}{ Average Land Holding (Acres) } \\
\cline { 2 - 3 } & & By District & By Region \\
\hline \multirow{3}{*}{ Northern } & Lira & 5.7 & \multirow{2}{*}{8.2} \\
& Dokolo & 6.0 & \\
\cline { 2 - 3 } & Otuke & 15.2 & \\
\cline { 2 - 3 } & Alebtong & 5.8 & \multirow{2}{*}{7.2} \\
\hline \multirow{2}{*}{ Eastern } & Iganga & 3.7 & \\
\cline { 2 - 3 } & Bugiri & 10.5 & 3.7 \\
\cline { 2 - 3 } & Kamuli & 7.4 & \\
\hline Central & Kayunga & 3.7 & \\
\hline
\end{tabular}




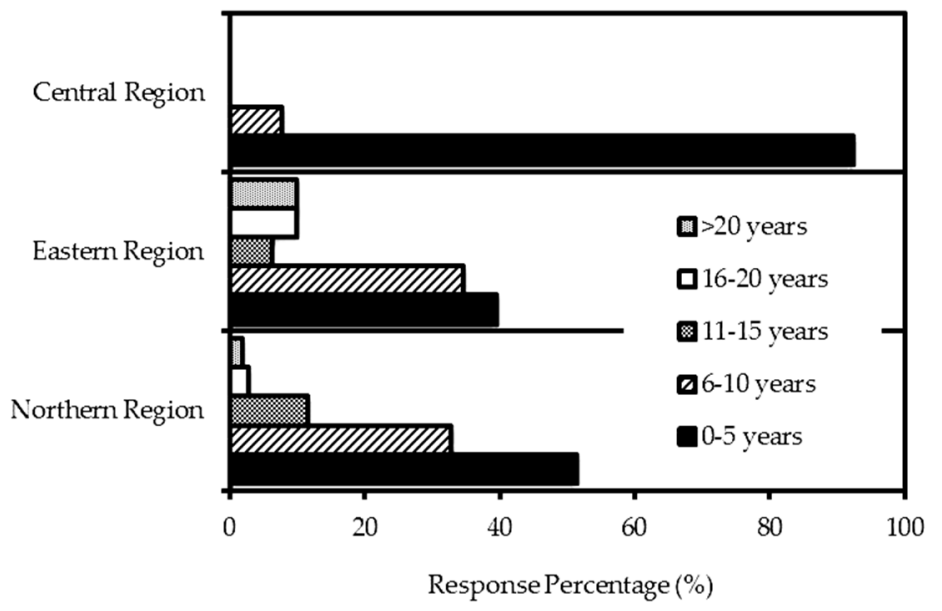

Figure 2. Years of experience of the respondents in rice farming. The total number of respondents for the northern, eastern and central regions was 113, 81 and 26, respectively.

\subsection{Rice Production Constraints}

The five most important constraints in rice production were insect pests, diseases, weeds, financial constraints and birds, as shown in Figure 3. Financial limitations were related to production costs such as tractor hire and hire of labor for various production operations performed, especially when family labor is inadequate.

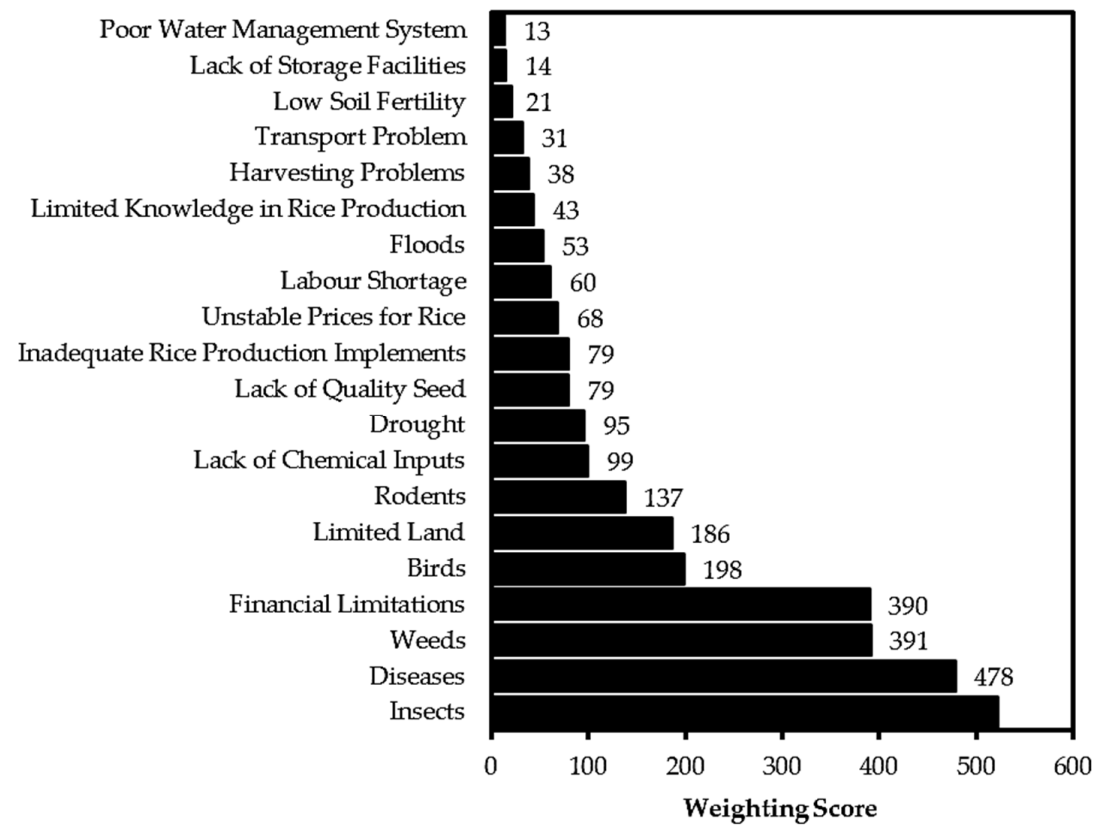

Figure 3. Rice production constraints in the survey areas.

\subsection{Farmers Knowledge and Perceptions on Rice Insect Pests}

When asked to list and rank rice insect pests according to their importance, respondents ranked stem borers and the African rice gall midge (AfRGM) as the 1st and 2nd most detrimental insect pests on rice (Figure 4). These were closely followed in rank by the rice bugs, leaf folders, armyworm, cutworm and termites in decreasing order. Other insect pests included rice hoppers, rice hispa, mole crickets, root weevils and grasshoppers among others. 


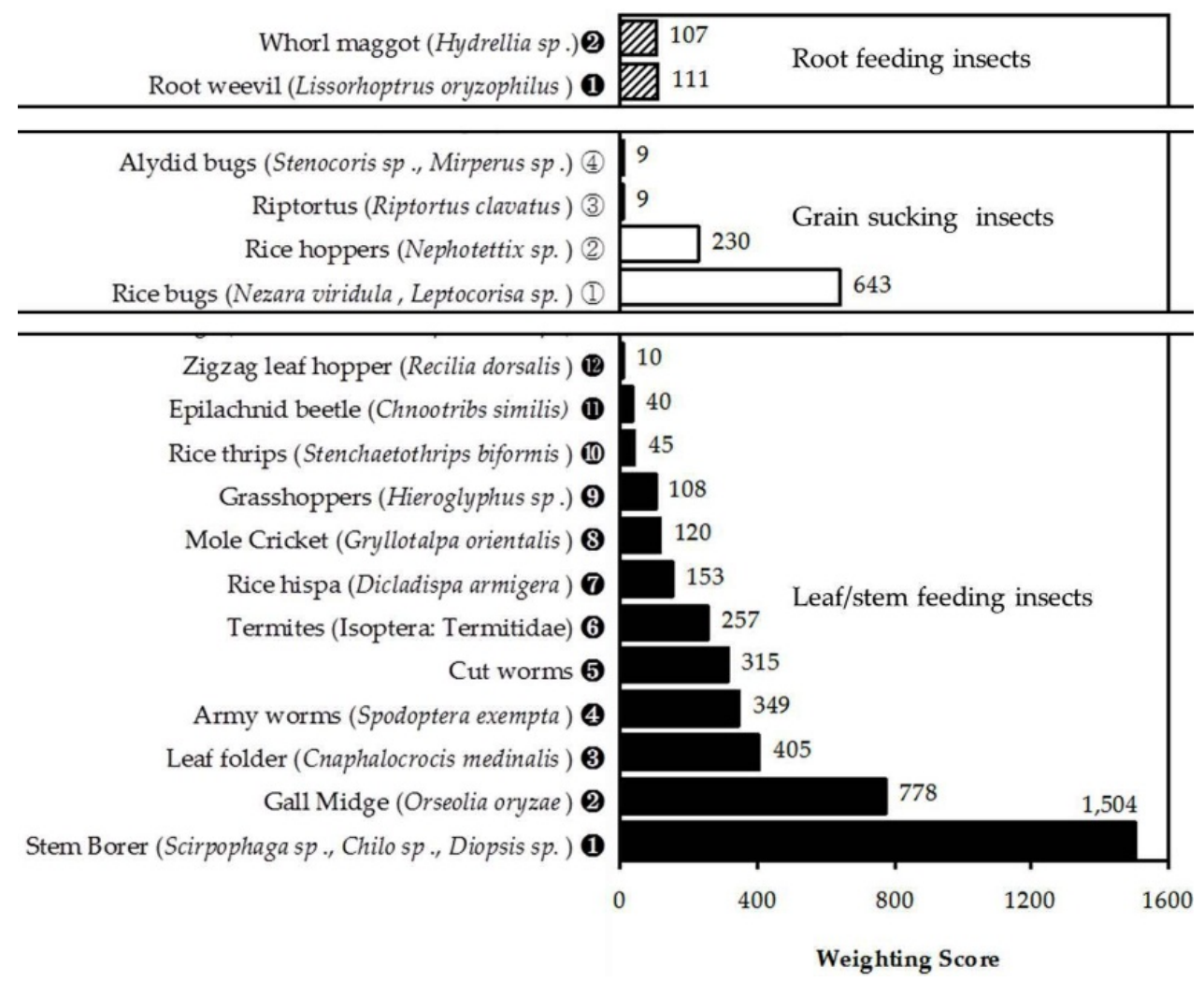

Figure 4. Farmer ranking of rice insect pests by category and according to importance on rice.

Rice insect pests were broadly categorized into three groups, namely, leaf/stem feeding insects, grain sucking insects and root feeding insects. Generally the leaf/stem feeding insects or defoliators seemed to dominate over other categories — going by the high average weighting score (340). Grain sucking insects came second in importance with an average weighting score of 223, while root sucking insects were considered the least important insect-pest problem scoring only 109. The most important leaf/stem feeding insect-pests according to the farmers were the stem borer, African rice gall midge (AfRGM) and leaf folders. Rice bugs were considered the most significant pest among the grain sucking insects while root feeding insects such as the root weevil and whorl maggot were perceived as minor pests.

\subsection{How Farmers Control Common Rice Insect Pests}

The five most important rice-insect pests as perceived by the farmers were stem borers, African rice gall midge (AfRGM), rice bugs, leaf folders and the armyworm. One interesting finding that emerged from this survey is that only about $40 \%$ of the farmers who were interviewed could correctly identify major insect pests of rice or symptoms that they cause (Figure 5).

Over two thirds $(72.3 \%)$ of the 224 farmers who were interviewed did not implement any measure to control these pests. Less than one third of the respondents (27.7\%, 62 farmers) indicated practicing some kind of control measure against rice insect pests. Less than one third of the respondents (51 farmers, 22.8\%) targeted the five major insect pests mentioned above. The major strategies that these farmers adopted for managing the five insect pests were; early sowing, burning rice stubble, use of insecticide and adjusting fertilizer. Table 3 presents a breakdown of the response frequencies and percentages of farmers using control measures against the five major insect pests identified. 


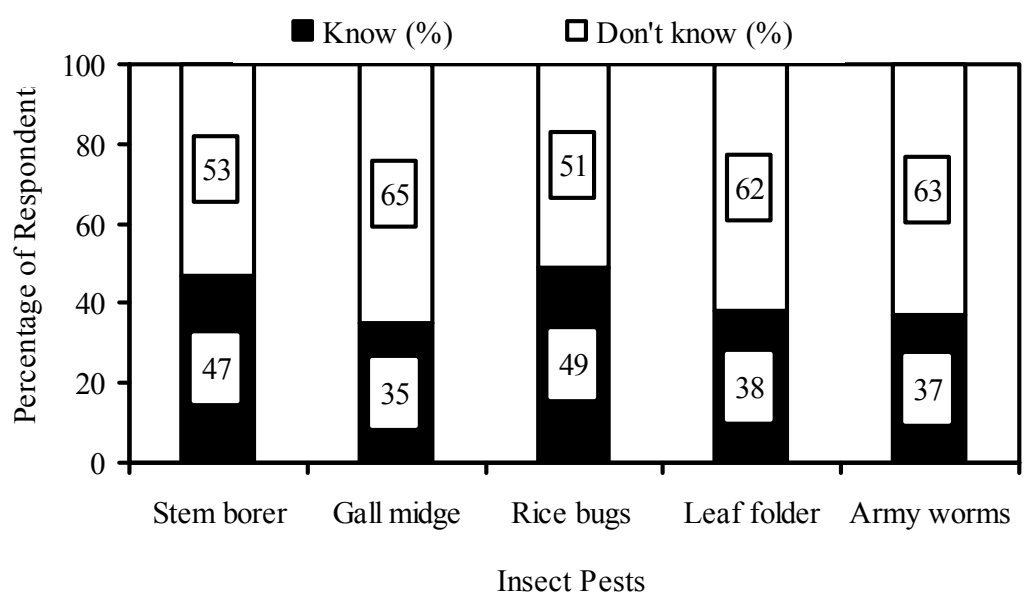

Figure 5. Proportion of farmer respondents who could correctly identify either the major insect pests of rice or their symptoms.

Table 3. Proportion of farmer respondents who use different control measures for the 5 major insect-pests of rice.

\begin{tabular}{cccccc}
\hline \multirow{2}{*}{ Control Measure } & Stem Borer & Gall Midge & Rice Bugs & Leaf Folders & Army Worm \\
\cline { 2 - 6 } & $\begin{array}{c}\text { Response } \\
\text { Frequency (\%) }\end{array}$ & $\begin{array}{c}\text { Response } \\
\text { Frequency (\%) }\end{array}$ & $\begin{array}{c}\text { Response } \\
\text { Frequency (\%) }\end{array}$ & $\begin{array}{c}\text { Response } \\
\text { Frequency (\%) }\end{array}$ & $\begin{array}{c}\text { Response } \\
\text { Frequency (\%) }\end{array}$ \\
\hline Early Sowing & $3(13.0 \%)$ & $1(8.3 \%)$ & $0(0 \%)$ & $0(0 \%)$ & $0(0 \%)$ \\
Adjusting fertilizer rate & $4(17.3 \%)$ & $1(8.3 \%)$ & $0(0 \%)$ & $2(33.3 \%)$ & $0(0 \%)$ \\
Burning rice stubble & $3(13.0 \%)$ & $1(8.3 \%)$ & $2(67 \%)$ & $1(16.7 \%)$ & $1(14.3 \%)$ \\
Using insecticides & $13(56.5 \%)$ & $9(75 \%)$ & $1(33 \%)$ & $3(50.0 \%)$ & $6(85.7 \%)$ \\
\hline Total & $23(100 \%)$ & $12(100 \%)$ & $3(100 \%)$ & $6(100 \%)$ & $7(100 \%)$ \\
\hline
\end{tabular}

It is apparent from this table that most farmers $(62.7 \%$ of all the respondents controlling the five major rice insect pests) rely on the use of insecticides to control rice insect pests. The least used pest management practice was early sowing. The burning of rice stubbles and adjusting fertilizer rates were moderately used. On the other hand, the only cultural control method that featured more (second to insecticide use) in the responses of the farmers was burning of rice stubble.

\subsection{Effectiveness of Control Measures}

The level of effectiveness of the control measure used on these five most common insect pests varied. Of the four respondents who reported controlling by sowing early (refer to Table 3), one said it is effective; while two said it was somewhat effective. One respondent said it was not effective. Seven respondents mentioned adjusting fertilizer rates as a way of managing rice insect pests. Two of these farmers noted that it is moderately effective and five said it was ineffective. Burning stubble as a way of managing insect pests was practiced by 10 farmers, seven of whom reported it to be moderately effective and three said that it is ineffective. Forty one farmers reported using insecticides to control insect pests. Of these, 15 farmers declared that insecticides were effective, while 24 said they were moderately effective. Two farmers reported that pesticides are not effective.

\subsection{Source of Information on Insect Pest Control Measures}

$58 \%$ of the farmers who were interviewed received information on insect control measures from fellow farmers, while $40 \%$ used their own experience. Only $2 \%$ received information from agricultural extension workers (Figure 6). 


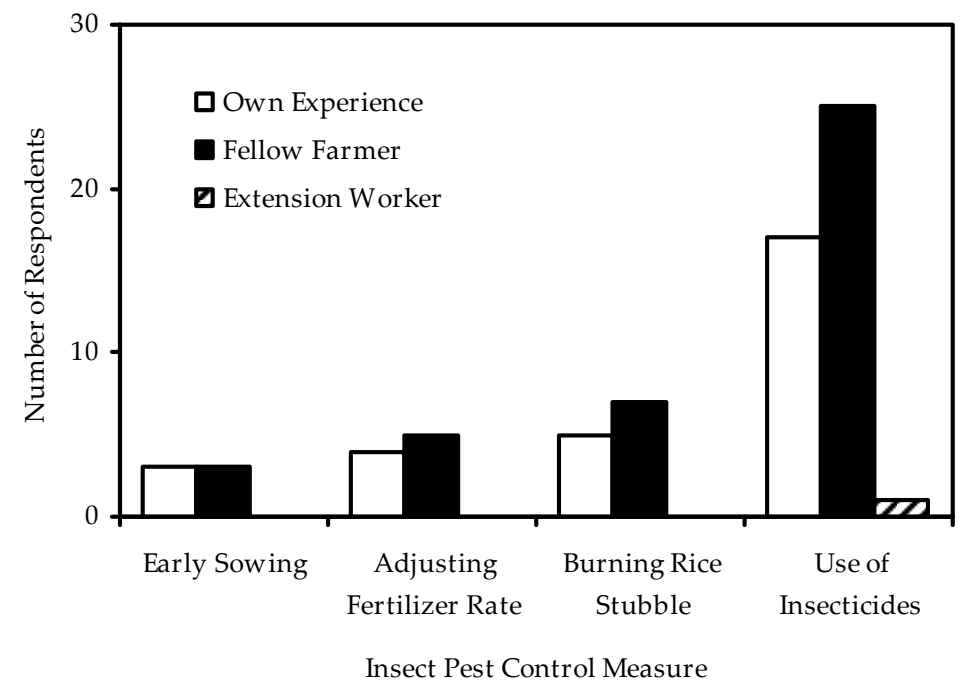

Figure 6. Farmers source of information for rice insect pest management.

\subsection{Farmers Knowledge and Perceptions of Weeds as Alternate Hosts of Rice Insect Pests}

When the farmers were asked whether they observe any of the rice insects on weeds/vegetation growing in and around their rice farms, 34 reported the presence of weeds, which are alternative hosts of rice insect pests in and around rice fields. Three of these farmers were from Lira, two from Otuke, eight from Alebtong, five from Iganga, seven from Bugiri, three from Kamuli and six from Kayunga. Some of the insects which live on weeds as perceived by farmers include the stem borer, gall midge, termite, leaf rollers and whorl maggot. On the other hand, some of the weeds that served as alternative hosts to rice insect pests included elephant or Napier grass (Pennisetum purpureum), sedges (Cyperus spp.), black-jack (Bidens pilosa), wandering Jew (Commelina benghalensis) and star grass (Cynodon dactylon). Elephant grass and star grass were infested by all the above insects, while $C$. benghalensis was infested by all except the rice gall midge. Sedges suffered infestation from the rice gall midge, termites and the whorl maggot. However, black jack harbored the gall midge and whorl maggot.

\section{Discussion}

The purpose of this study was to assess farmers' knowledge and perceptions about rice insect pests and how the farmers cope with them. The farmers interviewed were well aware of the importance of rice insect pests. They regarded insect pests as the number one production constraint, with diseases ranking 2nd and weeds 3rd. This is contrary to the findings of Diagne et al. [4], who found weed infestation to be the most important biotic constraint followed by insect pests and then birds [4]. This inconsistency may be due to the large differences between the 18 major rice-producing countries that were surveyed by Diagne et al. [4]. For instance, they found the average area affected by insect pests ranging from a low $11 \%$ in Guinea and a high $49 \%$ in Kenya. Hence our findings may be representative of the scenario in Uganda. Something clear from this study however is that insect pests constitute one of the major biotic constraints limiting rice production in Uganda just like any other country in Sub Saharan Africa (SSA), which is in agreement with the observation Lenne [5].

In all the districts surveyed, a majority of the farmers interviewed identified five insect pests as being of major importance. These included stem borers, the African rice gall midge (AfRGM), rice bugs, leaf folders and the army worm. Of these, stem borers were perceived to be the most detrimental of the rice insect pests. This situation appears to be similar across much of SSA [8]. Stem borers belong to the category of insects which feed on the leaves and stems of rice. Second to the stem borers amongst the leaf/stem feeders was the rice gall midge. The rice gall midge also ranks high among the important 
insect pests in SSA, and is a primary focus for control in rice fields [9]. Farmers rated rice bugs as the most harmful of the grain sucking insect pests. Rice bugs are important insect pests during the milky stage of rice and they feed by sucking the sap of developing spikelets causing serious rice crop losses. Root feeding insect-pests on the other hand were rated rather low in terms of importance.

A disheartening fact that emerged from the study however was that about $60 \%$ of the farmers who were interviewed could not correctly identify major insect pests of rice or symptoms they cause, which affects any attempts to control specific insect pest. Perhaps this explains why over two thirds of the farmers interviewed did not manage rice insect pests, presumably because they cannot identify the pests. Among the key pest control measures reported by the farmers were early sowing, burning rice stubble, use of insecticide and adjusting fertilizer rates. The predominant measure, which was also perceived by farmers as most effective, was the use of insecticides, while cultural control methods were under represented. The only cultural control method that was used frequently and also perceived to be effective is the burning of rice stubble. However, the perception that insecticides are the most effective control method for rice insect pests contradicts the principles of IPM. According to the World Bank, the main reason for unnecessary pesticide use is lack of knowledge and information among farmers about other crop protection approaches and the true costs and benefits of pesticide use [10]. This highlights a need to develop and sensitize farmers on aspects of IPM. Insecticides can be effective for controlling rice insect pests if used carefully and according to instructions. Injudicious pesticide applications however may result in insect-pest outbreaks. The best example is the emergence of the rice brown plant hopper (BPH). Prior to 1970, the BPH was a virtually unnoticed member of the fauna of tropical rice fields in Asia. Its rise as one of the most important pests of rice in South-East Asia was strongly associated with the overuse of pesticides [11].

Farmers were aware of the fact that weeds in and around rice fields are potential alternative hosts of rice insect-pests. The farmers identified elephant grass, sedges, black-jack wandering Jew and star grass as some of the alternative hosts of rice insect pests. Such farmer knowledge is valuable in understanding interactions between weeds and insect populations, and thereby aid in developing sustainable and cost effective IPM strategies.

\section{Conclusions}

Theoretically drafted strategies to control pest populations are bound to fail unless farmers, who are the major stakeholders, are involved from the beginning. The value of farmers' knowledge is their long and intimate association with the crop, their unlimited opportunities for observation during the whole cropping season and their comprehension of pest-crop dynamics within the agro-ecological landscape. By engaging them, a pest management strategy that is sustainable, safe and cost-effective can be designed and implemented [12]. For the development and implementation of sound insect-pest management practices, the following findings of our study are important: (1) stem borers, AfRGM, rice bugs, leaf folders, and army-worms are perceived by farmers as the major insect pests of rice in Uganda; (2) rice farmers are aware of the damage potential of insect pests; (3) rice farmers believe that insecticides are the most effective insect pest control measure; and (4) vegetation including weeds in and around the rice fields are perceived as alternative hosts of rice insect pests.

Acknowledgments: This study was supported by a World Bank funded Eastern Africa Agricultural Productivity Project (EAAPP).

Author Contributions: All the authors completed the study conception and design. M.H.O., S.E.A.O., J.L., M.E. and G.A. developed the study tools. S.A., M.H.O. and S.E.A.O. analyzed and interpreted the data. S.A., M.H.O., S.E.A.O. and M.E. wrote the draft of the manuscript. S.A., M.H.O., J.L. and G.A. did the critical revision of the manuscript. J.L. and G.A. supervised the EAAPP Project.

Conflicts of Interest: The authors declare no conflict of interest. 


\section{References}

1. Ministry of Agriculture, Animal Industries and Fisheries (MAAIF). Uganda National Rice Research Strategy (NRDS); MAAIF: Entebbe, Uganda, 2012.

2. Ahmed, M. Analysis of Incentives and Disincentives for Rice in Uganda; MAFAP, FAO: Rome, Italy, 2012.

3. Pingali, P.L.; Gerpachio, R.V. Living with reduced pesticide use in tropical rice in Asia. Food Policy 1997, 22, 107-118. [CrossRef]

4. Diagne, A.; Alia, D.Y.; Amovin-Assagba, E.; Wopereis, M.C.S.; Saito, K.; Nakelse, T. Farmer perceptions of the biophysical constraints to rice production in sub-Saharan Africa, and potential impact of research. In Realizing Africa's Rice Promise; Wopereis, M.C.S., Johnson, D.E., Ahmadi, N., Tollens, E., Jalloh, A., Eds.; CABI: Accra, Ghana, 2013; pp. 46-68.

5. Lenné, J. Pests and poverty: The continuing need for crop protection research. Outlook Agric. 2000, 29, 236-250. [CrossRef]

6. Warburton, H.; Martin, A.M. Pest management and poor people. In 1999 BCPC Symposium Proceedings No. 73 : International Crop Protection: Achievements and Ambitions; BCPC: Farnham, UK, 1999; pp. 35-55.

7. StataCorp. Stata Statistical Software: Release 10; StataCorp LP: College Station, TX, USA, 2007.

8. Seck, P.A.; Diagne, A.; Mohanty, S.; Wopereis, M.C.S. Crops that feed the world: Rice. Food Secur. 2012, 4, 7-24. [CrossRef]

9. Oikeh, S.O.; Nwilene, F.E.; Agunbiade, T.A.; Oladimeji, O.; Ajayi, O.; Mande, S.; Tsunematsu, H.; Samejima, H. Growing Upland Rice: A Production Handbook; Africa Rice Center: Cotonou, Benin, 2008; p. 40.

10. The World Bank Group. Integrated Pest Management. Available online: http://go.worldbank.org/ F98SD7NLZ0 (accessed on 24 June 2014).

11. Joshi, R.C.; Shepard, B.M.; Kenmore, P.E.; Lydia, R. Insecticide-induced resurgence of brown planthopper (BPH) on IR62. Int. Rice Res. Newsl. 1992, 17, 9-10.

12. Aguilar, C.H.; Lasalita-Zapico, F.; Namocatcat, J.; Fortich, A.; Bojadores, R.M. Farmers' Perceptions about Banana Insect Pests and Integrated Pest Management (IPM) Systems in SocSarGen, Mindanao, Philippines. In Proceedings of the International Conference on Intelligent Agriculture, IPCBEE, Hong Kong, China, 13-14 February 2014; IACSIT Press: Singapore, Singapore, 2014; Volume 63.

(C) 2016 by the authors; licensee MDPI, Basel, Switzerland. This article is an open access article distributed under the terms and conditions of the Creative Commons Attribution (CC-BY) license (http://creativecommons.org/licenses/by/4.0/). 